\title{
Research on Dental Gold Alloys
}

\section{PAPERS PRESENTED AT THE IPMI CONFERENCE}

\section{Arun Prasad}

Rx Jeneric Gold Company, Inc., Wallingford, Connecticut, U.S.A.

During the second annual conference of the International Precious Metals Institute, held in May 1978 in New York, two sessions were devoted to dental application technology. The seven papers presented concerned recent developments in gold alloys and porcelains.

\section{Age-Hardening of Dental Silver-Palladium- Copper Alloys}

The high and fluctuating cost of gold has stimulated interest in the development of dental alloy systems less expensive than those based on high gold contents. One such development is based on the silver-palladium-copper system. Prior studies on the age-hardening of the silver 25 palladium $/ 7$ copper weight per cent alloy suggested two mechanisms: precipitation of CuPd ordered phase which has a CsCl-type structure and the formation of copper-rich Guinier-Preston zones. The addition of gold (less than 15 weight per cent) to silver-palladium-copper alloys affects these hardening mechanisms. This was discussed in a paper by $M$. Ohta, K. Hisatsune and $M$. Yamane of the Department of Dental Engineering at Kyushu University, Fukuoka, Japan.

Three commercial alloys, all in the composition range 49.3 to 52.5 silver/ 24.5 to 29.3 palladium/15.3 to 21.0 copper $/ 2.6$ to 6.5 gold atomic per cent, were used. Specimens were solution-treated at 900 to $930^{\circ} \mathrm{C}$ and aged anisothermally at a constant heating rate. Hardening characteristics were examined in relation to the structural changes by means of microhardness tests, electrical resistivity measurements, X-ray diffraction and optical and electron microscopy observations. It was concluded by the authors that the hardening of these gold-modified silver-palladiumcopper alloys occurs in two stages: stage I, from 200 to $300^{\circ} \mathrm{C}$ and stage $\mathrm{II}$, from 300 to $400^{\circ} \mathrm{C}$. Fine platelets of ordered $\mathrm{CuPd}$ are formed in stage I. In stage II, discontinuous precipitation at grain boundaries was observed and it was suggested that the development of fine lamellar structures (silver-rich and ordered phases) was responsible for hardening. Activation energies for stages I and II were calculated to be 1.0 and $1.5 \mathrm{eV}$ respectively. It is probable that the former corresponds to the migration of quenchedin vacancies and the latter to grain boundary diffusion.

\section{Age-Hardening Characteristics of a \\ Commercial Dental Gold Alloy}

Most dental gold alloys containing platinum and palladium exhibit strong age-hardening characteristics. Although knowledge of the hardening mechanism of commercial dental gold alloys is of great practical importance, only a few reports dealing with the subject have been published. The commercial dental alloy used in the studies of $\mathrm{K}$. Yasuda and $M$. Ohta, respectively from the Department of Dental Materials Science at Tokyo Medical and Dental University and the Department of Dental Engineering at Kyushu University, Japan, had the following composition: 66 gold $/ 11$ platinum $/ 6$ palladium $/ 6$ silver/9 copper weight per cent.

Electrical resistivity measurements made on a quenched wire specimen during reheating from room temperature to $800{ }^{\circ} \mathrm{C}$ showed two peaks: one at approximately 240 and the other at approximately $440^{\circ} \mathrm{C}$. Isochronous age-hardening curves also revealed two peaks at approximately 250 and $450^{\circ} \mathrm{C}$. These peaks marked the first and second stages of aging in the alloy. Electron microscopy results indicated that hardening in the first stage was due to the formation of the AuCu I type superlattice parallel to $\{001\}$ matrix planes. Simultaneous occurrence of ordering and precipitation was observed in the second stage. The lattice parameters of the disordered matrix, the AuCu I type superlattice and the precipitate were found to be $0.395,0.399$ and $0.3992 \mathrm{~nm}$ respectively. The axial ratio of the $\mathrm{AuCu}$ I type superlattice was approximately 0.9 . The authors suggested that during aging one unit cell edge of the disordered matrix contracts by 9.1 per cent to become the ordered $c$-axis, and the other two edges expand by 1 per cent to become ordered $a$-axes. It was also concluded that the grain-boundary precipitate did not contribute to agehardening.

\section{Electron Microscopic Studies of the Hardening} Mechanism in Type III Dental Gold Alloys

The type III dental gold alloy used in the investigation of T. Eng and K. Mukherjee of the Polytechnic Institute of New York, Brooklyn, N.Y., was the American Dental Association (ADA) certified commercial alloy named 'Firmilay' (a product of J.F. Jelenko \& Co., New Rochelle, N.Y.). The nominal composition of the alloy is $75 \mathrm{gold} / 3$ palladium $/ 11$ silver/10 copper/1 trace additions weight per cent. 
Electron microscopy and hardness measurements were used to study the hardening mechanism. All specimens were cold rolled, annealed, solution treated at $700^{\circ} \mathrm{C}$ for one hour and water quenched. They were then aged in a molten salt bath for times ranging from 0.5 to $24 \mathrm{~h}$ at temperatures between 250 and $450^{\circ} \mathrm{C}$. The results indicated an increase in the hardness of this alloy with aging time only at temperatures below $350^{\circ} \mathrm{C}$. Electron microscopy observation of the samples aged below $350^{\circ} \mathrm{C}$ revealed that hardening during the early stages of aging was due to the formation of an ordered phase on $\{001\}$ planes of the disordered matrix. Further aging allowed this second phase to be identified as the AuCu I type ordered tetragonal structure with a lattice parameter of $0.397 \mathrm{~nm}$ and a $c / a$ ratio of 0.93 . The authors did not observe any grain boundary precipitation.

\section{Notes on the Origin of Dental Porcelain for Fusion to Precious Metals}

It was not until 1962 that the use of gold alloys for porcelain bonding became a real possibility. The efforts behind this breakthrough have been well documented by Sigmund Katz, American Thermo Craft Co., East Orange, New Jersey, U.S.A.

The history of this development is bound up with the activities of the dental office of Drs. A. B. and $M$. Weinstein in New York City during the 1940's and 1950's. This office rejected the use of acrylic resins and the display of metal in the oral cavity resulting from the use of metals in dental restorations. Since materials for the practice of dentistry within such limitations were not available, they decided to undertake the development of them and the process of coating metal restorations with porcelain was evolved.

\section{Application of the Potentiokinetic Hysteresis Technique to Characterise the Chloride Corrosion of Dental Golds}

The corrosion resistance of dental casting alloys is usually evaluated by such techniques as immersion tests and vapour contact tests in a sulphide-containing environment. However, these tests are limited in that they are time consuming and subjective. In the past, composition limits served as a guide for optimum corrosion and tarnish resistance of high gold content alloys. Recently it has been demonstrated that such composition limits are not always a guarantee of satisfactory corrosion resistance. Thus, there is a need for a quick, convenient means of screening in the development of new dental alloys. Application for the purpose of the potentiokinetic hysteresis technique was emphasised in a paper by N. K. Sarkar of the Louisiana State University in New Orleans. This technique was used to study the corrosion behaviour, in a 1 per cent sodium chloride solution, of commercial dental casting gold alloys containing from 40 to above 75 per cent noble metals (gold and platinum group metals). Potentials in the range of -200 to $+400 \mathrm{mV}$ against a saturated calomel electrode (SCE) were applied. It was demonstrated that the low gold alloys, in general, are characterised by decreased chloride corrosion resistance when compared to certified ADA type III and IV gold alloys of minimum noble metals contents 78 and 75 per cent respectively. This decrease in resistance apparently results from the presence of silver-rich microsegregations on the precipitates. The amount of corrodible silver is easily estimated from the hysteresis peak in current density at approximately $-20 \mathrm{mV}$ vs. SCE. This peak current density was used to rank the alloys according to their corrosion resistance. The test requires only about an hour to perform.

\section{Application of Thermodynamics to Dental Alloy Research}

Thermodynamic principles and data are important to the understanding of materials and to the development of improved products as they can help to describe alloying characteristics, high temperature behaviour and properties of compounds.

Various authors have developed methods of using thermochemical data in order better to define the phase relations in binary and multi-component diagrams. If sufficient thermochemical data are available, the calculated diagrams are within experimental accuracy. When no information is at hand, empirical methods can be used to generate enough data for initial research purposes. In the paper by P. J. Cascone of J. F. Jelenko \& Co., New Rochelle, N.Y., the use was described of regular and sub-regular solution models to generate phase boundaries of gold-platinum, gold-palladium, gold-silvercopper and silver-palladium-copper systems.

\section{Modification of Dental Specifications for Precious Metal Alloys}

In August 1975, Deutsche Industrie Norm DIN 13 906, a specification for casting gold alloys which embodied modifications of the previous ADA Specification No. 5 was published in Germany. While maintaining previous chemical requirements it incorporates changes in the design of tensile samples and mechanical properties.

A subcommittee of the American National Standards Institute Committee MD 156 is drafting a new specification for conventional casting gold alloys and the alloys used as substrates for porcelain. The paper presented by Scott Brooks of J.M. Ney Co., Bloomfield, Connecticut, discussed these developments.

One of the important control parameters, omitted in prior ADA specifications, is the grain size range of the alloys being used for crown and bridge as well as for ceramic restorations. There is a strong possibility that grain sizes will be specified in the future American draft document. 